\title{
The Socio-Cultural Effects of Internal Migration among the People of Akutupa Kiri in the North-Central Zone, Nigeria
}

\author{
Sibiri, A. Elliot PhD \\ A Lecturer at the Department of Sociology, Faculty of Social Sciences \\ Niger Delta University Wilberforce Island Bayelsa State, Nigeria \\ Email Address: oyinkulesibiri@yahoo.com \\ Ayinmoro, A. Daniel \\ A Post-Graduate Student at the Department of Sociology/Demography \\ Faculty of Social Sciences, University of Ibadan, Ibadan Nigeria \\ Email Address: boluwajidaniel@gmail.com \\ Jack Jackson, T. C. B \\ A Post-Graduate Student at the Department of Sociology \\ Faculty of Social Sciences, University of PortHarcourt, Nigeria \\ Email Address: jackdon50@yahoo.com
}

\section{Doi:10.5901/mjss.2014.v5n15p494}

\section{Abstract}

The paper examines the socio-cultural effects of internal migration on migrants' households in Nigeria. Many factors have been accounted for the socio-cultural extinctions especially in local languages, traditional occupations and all the likes, but little or no attention has been given to the impact of internal migration on the current trend of this social phenomenon. A cross-sectional design as well as a triangulation of economic, push-pull and systems theories was utilized for the study. 160 migrants' households non-probabilistically participated in a snow ball method of data collection. Pie chart and linear multiple regression analysis were utilized for the study. Findings showed that there was significant relationship between internal migration and socio-cultural variables dislocations. Policy implications were made such that programmes that will facilitate socio-cultural activities at the places of destinations of migrants, as well as discouraging urban concentration of people such as deindustrialization of urban centres and promotes rural development.

Keywords: Even development, internal migration, migrants, migration stream, socio-cultural extinctions.

\section{Introduction}

Movement of people from one location to another is a common phenomenon in both developed and developing nations (Oyeniyi, 2013). The idea that one making up his choice and move to a location that promises better opportunities has long been an important part of human race. As such, population movement is usually deliberate. That makes the presence (or absence) of the movers in a place a matter of choice, not chance. The voluntary movement of people however, selects districts types of individuals from their origins (Morrison, Bryan and Swanson, 2004).

Indeed, migration trends in population dynamics have shown that internal migration rates are increasingly alarming particularly in Nigeria (see Oyeniyi, 2013). For different generations of internal migrants across regions, states, cities, towns and villages orchestrated by differences in education level, socioeconomic and political developments, these socioeconomic variables however play important roles in how internal migration impacts upon socio-cultural characteristics of the migration streams. Yet, policy makers and population experts have not paid much attention to this phenomenon across board especially its effects on the culture of the migrants.

Though the movement of people from one place to the other particularly rural-urban migration contributes tremendously to the socio-economic development and poverty alleviation of the migrants (Oyeniyi, 2013), the sociocultural dislocations the movement portends to the migrants have not been placed with much emphasis overtime. However, the consequences of migration and mobility typically affect more than just total numbers of inhabitants. 
Overtime, a population may be changed or transformed as people realize their intentions to enter or leave an area. A population composition may be altered with respect to age, sex, race, ethnicity, income, education and other socioeconomic characteristics (Morrison, Bryan and Swanson, 2004, p. 493), so also the socio-cultural characteristics of the migrants may be altered overtime.

However, an examination of migration is particularly important in the context of the current economic environment of slow job growth and depressed housing market activity, because individual relocation decisions often involve changes in employment and housing consumption (Molloy R., Smith C. L \& Wozniak A. 2010, p. 1); people also migrate from their places of origins to their destinations for reasons that are connected with workings of national economic and social systems. With a region mobility and migration patterns vary widely among areas, differences in migration patterns may occur, and their potential for rapid change in terms of social and cultural lifestyles may be affected (Morrison, Bryan and Swanson, 2004).

This paper examines the socio-cultural changes that occur among a selected migration stream in order to examine the extent to which internal migration has resulted to changes in the socio-cultural variables which include local language, family organization structure or cultural values, traditional food and traditional mode of dressing, among other sociocultural characteristics, as well as the underlying reasons predisposing migrants to move from the place of origin to the place of destination among the people of Akutupa Kiri who are residents of Kabba town in the North-Central zone, Nigeria.

\section{Statement of Problem}

Nigeria with more than 140 million people and a growth rate estimated at 2.5 per cent in 2010, Nigeria has a high urban growth rate. This urban growth, estimated at 3.84 per cent for the period 2005-2010 (UNPD, 2009), cannot be dissociated from migration, especially internal migration. According to Oyeniyi (2013), although the Nigerian Government has given increased attention to migration since the country's return to democracy in 1999, but very little concern for internal migration is emphasized. In Nigeria, scholars have made efforts in literature to link internal migration with environmental problems, in particular urban pollution and slum and ghetto development. Another trend in the literature on internal migration is the rural-urban nexus (Oyeniyi, 2013). Yet, little or no considerable effort to link internal migration to the extinction of local languages, cultural values, local dishes as well as the loss of traditional attires, among other critical cultural extinctions. In fact, empirical evidence to justify these is lacking. Though a few studies have analyzed internal migration dynamics (Oyeniyi, 2013) in terms of the reasons offered that predispose people to move in the literature (see Kpedekpo, 1982; Morrison, Bryan and Swanson, 2004), one issue that is still missing in this present generation is the impact of internal migration on the dislocation of the migrants' socio-cultural values. This study however, seeks to fill the gap through an investigative analysis of the impact of internal migration on socio-cultural characteristics of a selected migration stream in the north-central zone, Nigeria.

\section{Analytical Frameworks}

The economic theory of migration assumes that potential migrants rationally weigh the costs and expected returns of moving. If the expected returns exceed the costs, migration ensues. Thus, migrants are expected to move from lowincome to high-income area (Findley, 1982. p. 344). Factors like perceived probability of employment and the probability of earning higher income than the place of origins also motivate people to come by out-migration. Indeed, economists tend to view migration decision from as single event; but many sociologists and demographers conceptualize the process in two steps i.e a decision to leave, followed by a second decision concerning the destination (Findley, 1982). This however, culminates to the question of what happens to the migrants' socio-cultural characteristics at the place of destinations, as well as the socioeconomic characteristics despite the potential opportunities awaiting them at the place of their destinations?

The push-pull theory assumes that there are environmental, demographic, and economic factors (such as limited opportunities, tedious farm work, low wages, lack of social amenities, etc.) which predispose or push migrants out of places, regions or countries of origins; the attractive forces (of divergence opportunities, high wages, adequate social amenities, good education, access to good healthcare, etc.) lures people to places of their destinations (Lee, 1966). Newton's laws of gravity which states that two bodies attract each other with a force that is proportional to the product of their masses and inversely proportional to the square of the distance between them is thus applicable to the phenomenon of internal migration particularly the rural-urban migration in Nigeria. Yet, the socio-cultural consequences of the movers in the place of destinations are yet to be provided with considerable explanations. 
However, systems theory takes a holistic and critical approach to the phenomenon under investigation because it is usually referred to as an inter-disciplinary framework of analysis. As Buckley (1967) maintained three different kinds of systems exist: mechanical, organic, and socio-cultural. These three kinds of systems differ qualitatively and quantitatively in terms of the way they work as well as their degree of complexity and instability. Systems may also be described in terms of the degree to which they are open or closed. Open systems (e.g., socio-cultural systems) tend to respond to a greater range of fluctuations in the environment than closed systems do. Thus, closed systems are entropic because they tend to break down while open systems tend to be negentropic (i.e., they tend to elaborate structures instead of breaking down) such as the elaboration of socio-cultural variables among the migrants at the place of their destinations which may portend to socio-cultural diffusion and cultural characteristics going on extinctions.

Furthermore, socio-cultural systems are often purposive and goal-seeking due to their capacity to receive feedback from their environments. Feedback - which is the key to the cybernetic approach to systems analysis - allows analysts to take into account change, growth, friction, and evolution in their studies of social systems. So also, systems theorists emphasize the importance of internal processes such as morphogenesis (processes of system change) and morphostasis (processes of system maintenance) where social systems develop mediating systems for the purposes of maintenance and change (Buckley, 1967).

Subscribing to the same view, Luhmann analysis of systems theory of differentiation is closely connected to the view of evolution particularly on socio-cultural variables. According to Luhmann, differentiation is the means by which a system deals with changes in its environment. It tends to increase the amount of complexity in a given system - that is, as an environment changes, a system (e.g., behaviour or culture) will develop new behavioural patterns in order to deal with such changes. As he argues there are four forms of differentiation that occur, namely; segmentary, stratificatory, centreperiphery, and functional differentiation. The latter form of differentiation, according to him, is the most complex and problematic for modern society, since it means that problems are often displaced from the level of society to one of its subsystems (e.g., the problem of migration from one place to the other). In other words, the society is a world that can be observed only from within the system as a whole. In his view however, knowledge of society may be gained through the observation of the relationship between a society and its semantics, or the way in which a society describes itself (Vandenberghe, 1999).

\section{Brief Review of Literature}

Although no universally accepted definition of internal migration currently exists, the consensual definition of internal migration is any temporary or permanent movement of people from one area of a country to another area of the same country for the purpose, or with the effect of, establishing a new residence (ACP Observatory on Migration, 2011: 5; Kok, 1999:19 cf Oyeniyi, 2013). Morrison, Bryan and Swanson (2004) defined internal migration as the movement from one place to another within a particular country. Kpedekpo (1982) in his own view defined it as the change of place of usual residence and crossing of a political boundary. In this definition, the concept of residence is of particular significance to the definition of migration for it combines the two elements on which the definition must hinge - length of stray and purpose of stay in the area of arrival (Kpedekpo, 1982. p. 44) either temporarily or permanently. This therefore implies that internal migration involves only the movement of people that will only require changing of residence within the country without crossing the boundary of a country to another country.

Furthermore, a migrant is defined as a person who changes his usual place of residence, and if this change of residence involves crossing a national boundary it is referred to as international migration. Emigration and immigration refers to migration away from and into a given country respectively. Internal migration according to Kpedekpo (1982) is a term usually employed to refer to changes of residence within a nation and defined in terms of residential moves across boundaries which are often taken as the boundary or minor divisions of districts or regions of the country. Residential moves which do not result in crossing such a boundary are usually termed mobility. Out-migration and in-migration refer to internal migration from or a given area within a country. The area which the migrants depart is referred to as the area of origin and the place of arrival is called the area of destination. A migration stream consists of all moves or all migrants with a common area of origin and destination (Kpedekpo, 1982; Morrison, Bryan and Swanson, 2004).

Given the conceptualization of internal migration as clearly stated above, the movement, especially of members of sub-ethnic groups that may have been grouped with other ethnic groups to form a nation-state is significant to this study both at the origin and destination. Besides socioeconomic characteristics consequences of the migrants at both ends of migration, socio-cultural consequences are considerably significant to the movers linguistically, social structurally, among others, which is the major focus of this study. 


\section{Socio-Cultural Effects of Internal Migration}

In migration generally, cultural and social issues are a significant. Usually, when people leave a community, the social fabric of the community inevitably change at the place of destination overtime. Although the exact nature of the changes may vary in terms of socio-economic characteristics and socio-cultural variables, of course, this may be attributable to out-migration tendency to result in a greater integration of the village with outside communities. Thus, the remaining villages will know more about urban ways and will be more likely to adopt selected urban behaviours, especially the purchase of urban consumption goods and the desire for formal education (Findley, 1982). This is an indication that the patterns of behaviours of the migrants in terms of their indigenous cultural values would be indubitably affected.

As Findley (1982) further maintained, migration in any form increasingly involves the community in cash economy, and this involvement has several consequences for both cultural life and social structure of the migrants. It is truism that modern economic system (capitalist) exists in most cities and towns. So also, communal labour exchanges that exist in the place of origin which help to maintain ties among the community's kin groups in the place of destination prior to their migration may tend to weaken lineage ties already existed. Similarly, communal ties are further weakened by the adoption of prestige behavior based on consumption of urban goods rather than trade of services or produce (Findley, 1982).

Migration induces changes positively or negatively to any given migration stream. In this, family structure or social networks may be affected. This however, suggests substantial modification of traditional patterns of the migrants in terms of languages, feeding habit, mode of dressing and all the likes. Thus, neither are parents nor children immune to social consequences of migration regardless of the distance between the origin and destination. With family or clan members residing in more than one locality, it is possible for families to relocate children as the need arises. In fact, it is most common that children are sent to town where they live with relatives while attending schools. Most often than not, such mobility alters child's perception of its place in the world thereby resulting to socio-cultural dislocations relatively to their languages, food consumptions, mode of dressing and all the likes. In the same manner, where families have members living in both urban and rural areas, their social networks expand to include persons in both areas. This bridging facilitates cultural diffusion from city to countryside. The resulting diversity may enhance a family's flexibility in coping with the ups and downs of life (Findley, 1982), but the originality of the socio-cultural heritage of their origin may be positively or negatively affected.

\section{Materials and Methods}

The study was conducted in Kabba town following the migration stream of the people of Akutupa Kiri who had been residing in Kabba over a period of 5 years and above. Kabba town is located in Kogi State serving as the headquarters of Kabba/Bunu LGA in the North-Central zone, Nigeria; while Akutupa Kiri is a suburb of Kabba town. In other words, for the purpose of this study, Kabba town served as the place of destination while Akutupa Kiri was considered as the place of origin of the people whose socio-cultural values were investigated. The local language of the migration stream investigated is kiri, a dialect of Yoruba language, their traditional occupation is farming, traditional attires usually worn by them is buba, while their native food are amala, pounded yam (iyan), locust beans (iru), egunsi soup, aru soup, tankelekan soup, among others.

In an attempt to investigate the phenomenon under study, cross-sectional survey design was adopted. One hundred and sixty migrants' households $(n=160)$ participated in the study using snow balling sampling technique for their selections. However, the choice of snow balling was motivated by the nature of the study which was mainly meant to focus on a particular migration stream whose identities could only be known through their hometown association in the place of destination (arrival). Furthermore, in an effort to select the participants for the study, the researchers first contacted the leadership of the hometown association that made up the migration stream of the study from which each of the households' representative was contacted to be involved in the administration of questionnaire after which the next migrants' household to be involved was introduced until the researchers completed the total number of migrants' households that participated in the study. In this, non-probabilistic sampling technique was adopted for the study.

Quantitative data collected for the study were edited and cleaned to eliminate inconsistencies that could undermine validity of data. Thus, the instrument of questionnaire was used to collect data from respondents where questions related to their socio-cultural variables were asked and coded for easier quantitative analysis ranging from (0) don't know (1) no (2) Yes; and (0) undecided (1) occasionally and (2) always, where applicable. Data generated from pre-coded and fixedchoice questions were entered and analyzed using Statistical Package for Social Sciences (SPSS) and Ms Excel respectively. A descriptive analysis of data was undertaken using charts and linear multiple regression analysis of 
variables whose associated influence impacted strongly on the study to test hypothesis at the level of significance a $(P<$ 0.05). Ethical considerations were emphasized throughout the field work ranging from informed and voluntary consent as well as the assurance of anonymity and confidentiality of participants. Hence the rights of the study participants were respected throughout the research.

The Linear multiple regression equation goes thus,

$Y=f\left(X_{1}+X_{2}+X_{3}+\ldots X_{m}\right)$

Where $Y=$ Dependent Variable of the migrants' household

$\mathrm{X}_{1}=$ Family Structure

$X_{2}=$ Native Language

$X_{3}=$ Traditional Occupation

$\mathrm{X}_{4}=$ Cultural Festival

$X_{5}=$ Native Attire

$X_{6}=$ Native Food

\section{Key Variables}

In order to measure socio-cultural characteristics of the respondents relative to internal migration, questions were asked on six socio-cultural indicators as the socio-cultural index. Thus, questions were asked on the following socio-cultural indicators: (1) whether family organization structure of the migrants household remaining the same as the place of origin at the place of arrival, (2) whether migrants households still have the ability to speak native language fluently at the place of destination, (3) ascertaining the extent to which migrants are still engaged in traditional occupation at the place of arrival, (4) ascertaining the extent to which migrant households observe cultural festivals at the place of destination, (5) ascertaining the extent to which the migrants' households wear traditional (native) attires at the place of destination, (6) exploring the extent to which native food are cooked and eaten by the migrants' household at the place of destination.

\section{Results and Discussion}

\subsection{Migrants Household Composition}

Figure I shows that respondents whose households composition is between 5-9 (49\%) is the largest among the migration stream followed by respondents whose household composition is between 10-14 (20\%), so also, respondents whose household composition is less than $5(17 \%)$, the household composition above $15(14 \%)$ is the least. In this however, despite the variation in the households' composition is inconsequential to the objectives the study was meant to investigate.

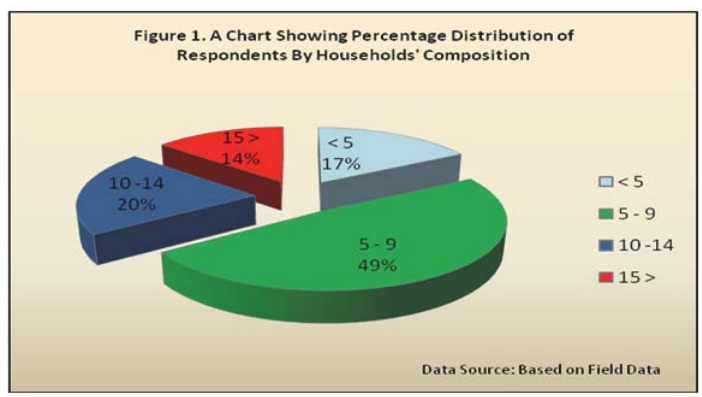

\subsection{Migrants' Motivated Factors for Internal Migration}

As indicated on figure II, the largest percentage (21\%) of the respondents was motivated the education factor to move to their present location, followed by $19 \%$ of them who were motivated by poor road networks to move, $14 \%$ low wages, $12 \%$ lack of electricity supply, $11 \%$ tedious farm work, $6 \%$ poor communication networks, $6 \%$ limited opportunities such as economic opportunities, $4 \%$ poor health care, $4 \%$ work transfer, $3 \%$ lack of portable water supply. This invariably support Lee's (1966) push-pull theory that there are factors that predispose migrants to move from one region to another 
region of which they tend to derive more benefits in their stay.

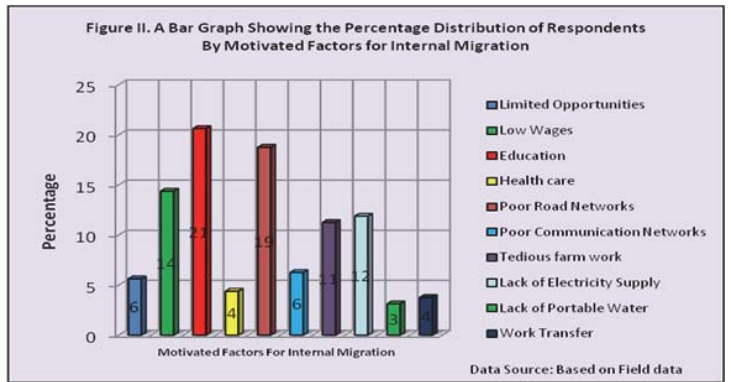

\subsection{Comparative Analysis of Migrants' Family Organizational Structure}

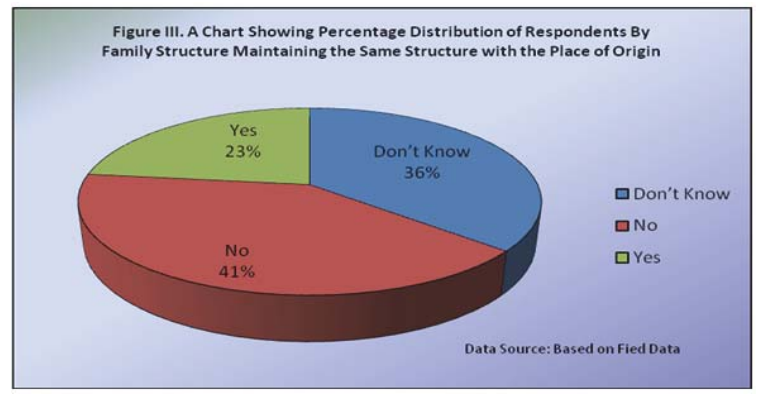

As indicated on figure III, respondents were asked whether they still maintain their family organizational structures in terms of types of family (extended or nuclear) as well as family authority and leadership, the largest percentage of them said 'No', followed by $36 \%$ of them who said 'Don't know', while the remaining percentage (23\%) agreed to the fact that the pattern of their family structures had not changed from their place of origin despite the move to a new destination. This however, suggests that the percentages of respondents who said 'No and Don't know' are undoubtedly affected by the move from their place of origin socio-culturally.

\subsection{Migrants' Native Language Fluency in the Place of Destination}

As shown on figure IV, respondents were asked whether they speak their native language fluently in the place of their destination as migrants' households, the larger percentages of the respondents said 'No' (36\%) and 'Don't Know' (36\%) respectively, while very few of them said 'Yes' as to the speaking of the native language fluently at the place of destination. This implies that the larger percentage of migrants household at the place of destination do not speak their native language fluently.

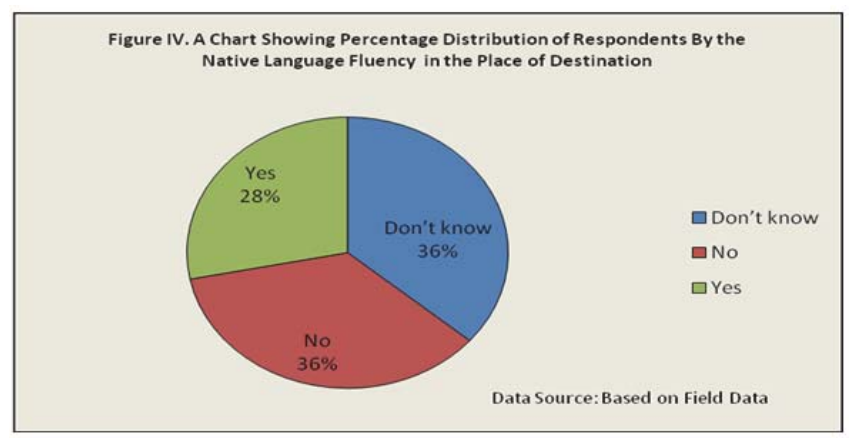




\subsection{Migrants' Traditional Occupation in the Place of Destination}

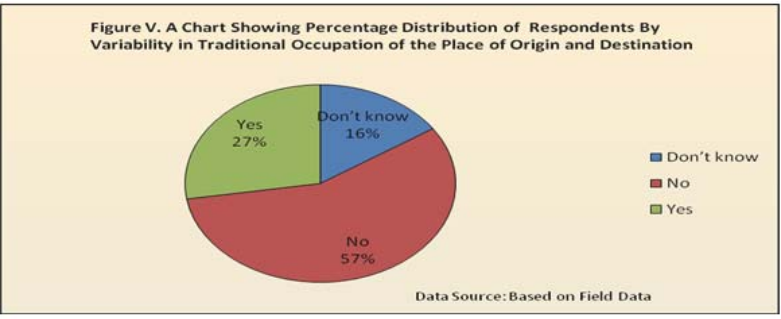

As indicated on figure $\mathrm{V}$, respondents were asked whether their traditional occupation remian the same in the place of destination as the place of destination, $57 \%$ of them 'No', 16\% said 'Don't Know', while $27 \%$ said 'Yes'. This simply implies that the larger proportion of the migrants households do not engage in their traditional occupation despite their move to a new destination.

\subsection{Migrants' Cultural Festivals Observation in the Place of Destination}

Figure $\mathrm{VI}$ shows the result of the respondents who were asked whether they observe their cultural festivals in the place of destination, the larger percentages responded 'No' (65\%) and 'Don't Know' (22\%) respectively, while only 13\% of them said 'yes' as to observing cultural festival in the place of their destination which only include celeberation of yam festival. This invariably suggests that very few migrants households mark the celeberation of cultural festival inspte their move to a new place of residence.

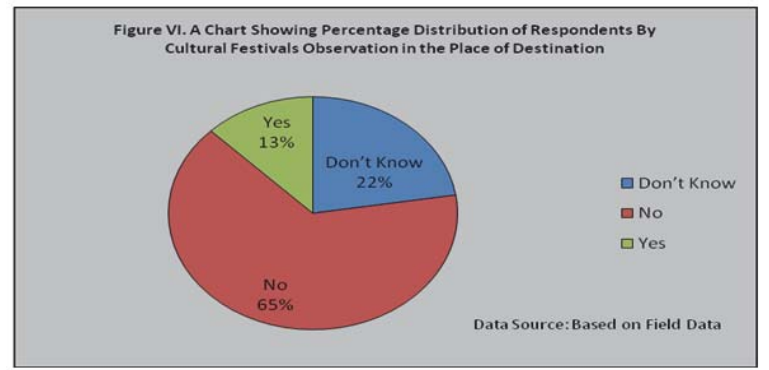

\subsection{Migrants Frequency of Wearing Native Attires in the Place of Destination}

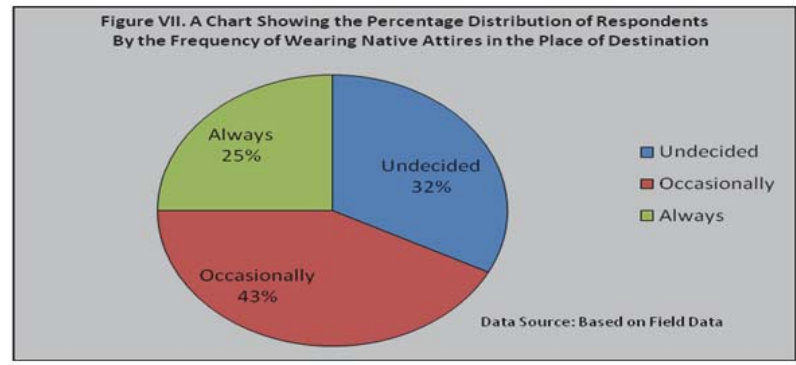

As indicated on figure VII, respondents were asked the frequency to which they wear their native attires in the place of destination, $43 \%$ of them said 'occasionally', $32 \%$ siad 'undecided', while only $25 \%$ of them said 'Always' as to the waering of their native attires in the place of destination. This implies that the very percntage of the respondents who said 'always' as to the wearing of their native (traditional) attires at the place of destination even after their move from the place of origin to the place of destination is insignificant compare to those who said 'occasionally and undecided'. 


\subsection{Migrants Frequency of Cooking and Eating of Native Food in the Place of Destination}

As revealed on figure VIII, respondents were asked the frequency of cooking and eating native food in the place of destination, the larger percentages said 'No' (54\%) and 'Undecided' (24\%) respectively, while $22 \%$ of them said 'Always'. This undoubtedly suggests that very few of migrants households cook and eat their native food in the place of destination.

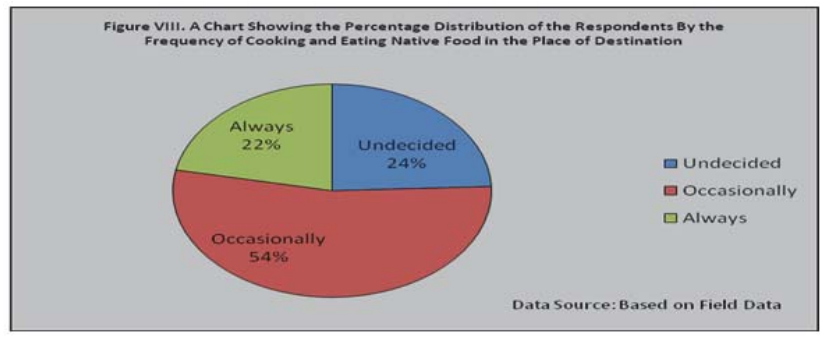

\subsection{Test of Hypothesis}

$H_{0} \neq$ There is no positive relationship between internal migration and socio-cultural variables dislocations.

$\mathrm{H}_{1}=$ There is a positive relationship between internal migration and socio-cultural variables dislocations.

Table I. A Summary Table Showing the Linear Muiltiple Regression Coefficients Analysis on Internal Migration and Socio-Cultural Varibles

\begin{tabular}{lccc}
\hline \multicolumn{1}{c}{ Variables } & Coefficients & SE & Sig. \\
\cline { 2 - 4 } 1 (Constant) & 3.109 & 0.271 & 0.000 \\
Family Structure & -0.115 & 0.095 & 0.227 \\
Native Language & -0.015 & 0.09 & 0.864 \\
Traditional Occupation & -0.303 & 0.11 & 0.007 \\
Cultural Festival & -0.334 & 0.121 & 0.007 \\
Native Attire & 1.159 & 0.092 & 0.084 \\
Native Food & 0.106 & 0.103 & 0.303 \\
\hline
\end{tabular}

Data source: Field Data, 2013. $n=160 ; \mathrm{SE}=$ Standard Error

$F(6,153)=3.961$

$\mathrm{p}<.005(0.000<0.005)$

$\mathrm{R}^{2}=.134$

Durbin-Watson $=.146$

a. Predictors: (Constant), Native Food, Traditional Occupation, Native Attires, Family Structure, Cultural Festival, Native Language

b. Dependent Variable: Migrants' Household

A multiple regression was run to predict migrant households' characteristics from family structure, native language, traditional occupation, cultural festivals, native attires, native food. These variables statistically significantly predicted migrants' household socio-cultural characteristics, the F-ratio in the ANOVA tests whether the overall regression model is a good fit for the data. It therefore shows that $F(6,153)=3.961, p<.005, R^{2}=.134$, Durbin-Watson $=.146$. All six variables added statistically significantly to the prediction, $p<.05$. This also tests whether the unstandardized (or standardized) coefficients are equal to 0 (zero) in the population. Thus, if $p<.05$, we can therefore conclude that the coefficients are statistically significantly different to 0 (zero). From table I, "Sig." column shows that all independent variable coefficients are statistically significantly different from 0 (zero) which satisfies the regression of variables. In regards to this, the alternative hypothesis is accepted because there is sufficient evidence to show that all independent variables can predict the dependent variable (migrants' household). In other words, as indicated on columns coefficient column, the column shows that the more socio-cultural variables of the migrants household depreciate the less likely socio-cultural characteristics of the migrants' household in terms of qualities. This therefore strongly affirms the fact that internal migration and socio-cultural variables are related. 


\subsection{Suggestions to Reduce Internal Migration Problem}

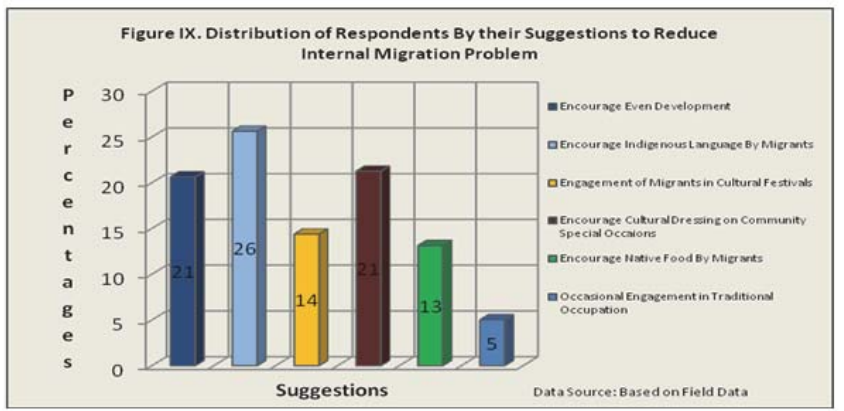

Respondents were asked to suggest likely solutions to reduce internal migration problem (see figure IX), the largest percentage (26\%) of the respondents suggested speaking of indigenous language of the migrants should be encouraged at their destination, $21 \%$ of them suggested that migrants should be encouraged to wear their cultural dressings on their community special occasions and encourage even development across board by the government respectively, 14\% of them suggested the engagement of the migrants in cultural festivals when they are observed in their respective communities, $13 \%$ of them suggested encouragement of native food by the migrants at the place of destination, while the least of them (5\%) suggested occasional engagement of the migrants in their traditional occupation. This invariably suggests that all likely solutions suggested irrespective of the percentages of the respondents may be of relevance to the subject of our investigation in the study.

\section{Conclusion and Policy Implications}

The central objective of the study was to carry out an investigative analysis of the socio-cultural effects of internal migration on selected migration stream. From the foregoing and with considerable evidences indicated on the empirical analysis of the study, internal migration has significant and considerable effects on migrants' socio-cultural variables such as the family structure, traditional occupation, native language, native food, cultural festivals, as well as the migrants traditional attires. This however, invariably concurs with the view of societal melting pot of the indigenous people in terms of socio-cultural practices. In other words, besides the consequences of globalization on the socio-cultural characteristics, internal migration has also played very significant role in the dislocations and extinctions of socio-cultural characteristics of the indigenous people of diverse cultures in the country. Factors responsible for the disgruntle socio-cultural environment are attributable to uneven development in the areas of distribution of infrastructure and social amenities across the two major dichotomized societies we have in existence (rural and urban centres) in the country.

In the view of the findings of the study however, considerable measures are required to resuscitate efforts by all and sundry to reduce the magnitude of socio-cultural characteristics going on extinctions as premeditated by internal migration through government efforts in facilitating even development across the country, encouraging programmes that would promote the use of indigenous languages, native food, traditional attires, as well as cultural festivals of the migrants at all levels on the media or at government special functions. Finally, efforts to de-industrialize the urban centres in order to discourage rural-urban migration should be advocated. This can be done by encouraging the establishment of agro-allied industries at the countryside, as well as further encourage mechanized agricultural practices at the rural areas. Doing these however, would go a long way to reduce internal migration through rural-urban migration which in turn helps to reduce the extinctions of the originality of socio-cultural characteristics of the indigenous people across cultures.

\section{References}

Buckley, W. (1967). Sociology and Modern Systems Theory. (http://highered.mcgraw-hill.com/sites/0072817186/ student_view0/chapter9/chapter_summary.html<Accessed on September 28, 2013)

Findley, S. E. (1982). Internal Migration: Determinants, Model and Effects. In: International Encyclopedia of Population. New York; The Free Press. P. 344-364

Kpedekpo, GMK. (1982). Essential Demographic Analysis for Africa -Studies in the Economic of Africa. London, Heinemann Educational Books Inc. p.145-146. 
Lee, E.S. (1966). A Theory of Migration. University of Pennsylvania. (http://www.jstor.org/stable/2060063. Accessed on July 10, 2013). Molloy R., Smith C. L \& Wozniak A. (2010). Internal Migration in the US: Updated Facts and Recent Trends (www3.nd.edu/../migrationmsw.pdf<Accessed on 23/10/2013).

Morrison, P. A., Bryan, T. M. \& Swanson, D. A. (2004). "Internal Migration and Short-Distance Mobility". In: Siegel, J. S. \& Swanson, D. A. (eds). The Methods and Materials of Demography Second Edition. London, Elseviers Inc. p. 493-519

National Planning Commission. (2012). Nigeria's total population was put at 140,431,790. See "2006 Population and Housing Census" at http://www.population.gov.ng/, accessed on 12 December 2012.

Oyeniyi, B. A. (2013). Internal Migration in Nigeria: A Positive Contribution to Human Development (www.acpmigrationobs.org/node/7314< Accessed on October 20, 2013)

United Nations Development Programme. (2009). Human Development Report 2009: Overcoming Barriers: Human Mobility and Development, available at http://hdr.undp.org/en/reports/global/hdr2009/; accessed on 19th June 2012

Vandenberghe, F. (ed). (1999). Niklas Luhmann's (1927-1998) Systemic Supertheorist of the Social published in Radical Philosophy (http://www.academia.edu/511002/Niklas_Luhmann_1927_1998_Systemic_supertheorist_of_the_social<Accessed on

September 29, 2013) 